\title{
The scimitar syndrome: clinical spectrum and surgical treatment
}

\author{
F.M.N.H. Schramel*, C.J.J. Westermann**, P.J. Knaepen+, J.M.M. van den Bosch**
}

The scimitar syndrome: clinical spectrum and surgical treatment. F.M.N.H. Schramel, C.J.J. Westermann, P.J. Knaepen, J.M.M. van den Bosch. CERS Journals Ltd 1995.

ABSTRACT: We present seven patients with the scimitar syndrome. The clinical and anatomical spectrum is described.

Two different types of scimitar vein were recognized. a) simple classic vein running from the middle of the right lung to the cardiophrenic angle (5 patients) and b) double arched vein in the upper and lower lung zone, with ample drainage into the left atrium and inferior caval vein ( 2 patients).

Four patients required surgical treatment. Indications, diagnostic procedures and surgical management are discussed. In two patients, thrombosis and fibrosis occurred in the scimitar vein that had been reimplantated in the left atrium, necessitating pneumonectomy.

Eur Respir J., 1995; 8: 196-201.
*Dept of Pulmonary Disease, Free University Hospital, Amsterdam, The Netherlands. **Dept of Pulmonary Disease and ${ }^{+}$Dept of Thoracic and Cardiovascular Surgery, St. Antonius Hospital, Nieuwegein, The Netherlands.

Correspondence: F.M.N.H. Schramel

Free University Hospital

De Boelelaan 1117

1007 MB Amsterdam

The Netherlands

Keywords: Complications, scimitar syndrome, surgery

Received: June 17 1994. Accepted after revision November 171994
The first case report of pulmonary venous drainage into the inferior vena cava was published in 1836 by COOPER [1]. The scimitar syndrome was named by NEILL et al. in 1960, describing a syndrome of partial anomalous pulmonary venous drainage of the right lung into the inferior vena cava, partial systemic arterial blood supply, and hypoplasia of the affected lung, with bronchial abnormalities and abnormal lobation [2]. Pulmonary venous drainage into the right atrium, superior vena cava, the azygos system, the hepatic vein, or the left atrium has also been described [3-10]. Rarely, a scimitar syndrome of the left lung has been reported $[11,12]$.

The scimitar syndrome is part of a variety of congenital disorders known as "partial anomalous pulmonary venous connection" (PAPVC). PAPVC is found in $0.4-0.7 \%$ of adults at autopsy [13]. The scimitar syndrome forms about $3-5 \%$ of all PAPVC [14, 15].

The pathogenesis of the syndrome is unclear, but it seems to originate from a basic developmental disorder of the entire lung bud early in embryogenesis [1618].

In the past, several case reports have been published describing the scimitar syndrome. To our knowledge, only four studies have presented a series of more than five patients with this syndrome; and few patients of these series underwent surgery $[3-5,17]$. Because of its rareness, we present seven patients with scimitar syndrome with variable congenital malformations of the right lung. Four patients underwent surgical therapy. It is clear from the past that surgical intervention is not always indicated and sometimes troublesome and complex.

\section{Patients and methods}

Seven patients ( 6 females, 1 male) with the scimitar syndrome are described, who were referred to our hospital in the 1967-1992 period. Results of bronchoscopy, bronchography and angiography of the aorta, pulmonary arteries and veins are summarized in table 1 . From the angiographic studies, it is often difficult to establish the exact lobar drainage due to absent or abnormal lobation. Therefore, in several patients (Nos 1, 2, and 5-7) the vascular drainage areas are defined as lung zones.

Table 2 shows the functional parameters of the seven patients. Vital capacity (VC) and forced expiratory volume in one second $\left(\mathrm{FEV}_{1}\right)$ were obtained by spirometry. Right lung perfusion was directly measured by lung scintigraphy with human albumin macroaggregates labelled with 99mtechnetium (patients Nos 2, 3, 6 and 7), or indirectly by bronchospirometry (patient No. 4). Cardiac catheterization was performed in order to measure pulmonary artery pressure (patients Nos 1, 3, 4 and 7), and to calculate left/right shunt by means of the oxygen saturation in the caval veins, pulmonary artery, pulmonary vein and aorta (patients Nos 1-4 and 7).

Table 3 shows the surgical management and postoperative course of four patients (patients Nos 1-4) and the follow-up of all seven patients.

\section{Patient No. 1}

In 1967, a 4 year old girl was referred to our hospital for evaluation of a heart murmur. Her medical history revealed recurrent episodes of chest infection. Physical 
Table 1. - Congenital anatomical abnormalities of the right lung

\begin{tabular}{|c|c|c|c|}
\hline $\begin{array}{l}\text { Pat. } \\
\text { No. }\end{array}$ & Malformations & Abnormal pulmonary venous drainage & Systemic arteries \\
\hline 1 & $\begin{array}{l}\text { Hypoplasia of bronchial tree, } \\
\text { trifurcation of main bronchus }\end{array}$ & $\begin{array}{l}\text { Upper lung zone to superior caval } \\
\text { vein and left atrium, lower lung zone } \\
\text { to inferior caval vein }\end{array}$ & 3 to middle and lower lung zone \\
\hline 2 & $\begin{array}{l}\text { Hypoplasia of bronchial tree, } \\
\text { absent lobation }\end{array}$ & $\begin{array}{l}\text { Lower lung zone to inferior caval } \\
\text { vein and left atrium }\end{array}$ & 3 to lower lung zone \\
\hline 3 & $\begin{array}{l}\text { Hypoplasia of lung, separate } \\
\text { pleura of middle and lower lobe }\end{array}$ & $\begin{array}{l}\text { Upper lobe to inferior caval vein, lower } \\
\text { and middle lobe to inferior caval vein }\end{array}$ & 5 to middle and lower lobe \\
\hline 4 & $\begin{array}{l}\text { Hypoplasia of bronchial tree, } \\
\text { separate pleura of lower lobe, } \\
\text { mirror image left bronchial system }\end{array}$ & $\begin{array}{l}\text { Upper lobe to inferior caval vein, lower } \\
\text { lobe to inferior caval vein and left atrium }\end{array}$ & $\begin{array}{l}3 \text { to lower lobe, } \\
1 \text { to upper lobe }\end{array}$ \\
\hline 5 & $\begin{array}{l}\text { Absent dorsal bronchus of upper } \\
\text { lobe and apical bronchus of lower } \\
\text { lobe }\end{array}$ & $\begin{array}{l}\text { Upper lung zone to left atrium and scimitar } \\
\text { vein, lower lung zone to inferior caval vein }\end{array}$ & \\
\hline 6 & $\begin{array}{l}\text { Hypoplasia of lung, mirror image } \\
\text { left bronchial system }\end{array}$ & Lower lung zone to inferior caval vein & \\
\hline 7 & Tracheal bronchus & $\begin{array}{l}\text { Upper lung zone to left atrium and scimitar } \\
\text { vein, lower lung zone to left atrium and } \\
\text { inferior caval vein }\end{array}$ & 1 to lower lung zone \\
\hline
\end{tabular}

Pat.: patient.

Table 2. - Results of spirometry, lung scintigraphy, bronchospirometry and cardiac catheterization

\begin{tabular}{lccccc}
\hline $\begin{array}{c}\text { Pat. } \\
\text { No. }\end{array}$ & $\begin{array}{c}\text { VC } \\
\text { pred }\end{array}$ & $\begin{array}{c}\mathrm{FEV}_{1} / \mathrm{VC} \\
\% \text { pred }\end{array}$ & $\begin{array}{c}\dot{\mathrm{Q}} \text { right lung } \\
\%\end{array}$ & PAP & $\begin{array}{c}\text { Left/right shunt } \\
\%\end{array}$ \\
\hline 1 & 76 & 78 & $\mathrm{nk}$ & $\mathrm{N}$ & 20 \\
2 & 80 & 88 & 9 & $\mathrm{~N}$ & $\mathrm{nk}$ \\
3 & 73 & 89 & 35 & $\mathrm{~N}$ & 25 \\
4 & 66 & 69 & 38 & $\mathrm{~N}$ & 40 \\
5 & 90 & 90 & $\mathrm{nk}$ & $\mathrm{nk}$ & $\mathrm{nk}$ \\
6 & 98 & 91 & 43 & $\mathrm{nk}$ & $\mathrm{nk}$ \\
7 & $\mathrm{nk}$ & $\mathrm{nk}$ & 43 & $\mathrm{~N}$ & 20 \\
\hline
\end{tabular}

Pat.: patient; \% pred: percentage of predicted; N: normal; VC: vital capacity; $\dot{Q}:$ perfusion; $\mathrm{FEV}_{1}$ : forced expiratory volume in one second; PAP: pulmonary artery pressure; nk: not known.

examination showed an underdeveloped girl. A chest radiograph demonstrated enlargement and displacement of the heart to the right, with two curved shadows, one right paracardial and one right paratracheal. Bronchoscopy, bronchography and intra-arterial angiography of the aorta, pulmonary arteries and veins were performed.

A scimitar syndrome was diagnosed, with abnormal venous drainage of the entire right lung and systemic arterial blood supply of the right lower lung zone.

Because of recurrent right-sided pneumonias, at $6 \mathrm{yrs}$ of age, right-sided thoracotomy was performed. The right lower lung zone drained via a scimitar vein into the inferior vena cava, at the level of the hepatic vein. The right upper lung zone drained via an abnormal lung vein into the superior vena cava, and via a normal pulmonary vein. The right pulmonary artery was hypoplastic. There were three systemic branches of the abdominal aorta running to the right lower and middle lung zone. Right pneumonectomy was performed. The postoperative course was uneventful. The follow-up until 1987 was unremarkable.

\section{Patient No. 2}

In 1972, a 29 year old woman presented with recurrent chest infections, shortness of breath and fatigue. The chest radiograph showed displacement of the heart to the right, a reduced volume of the right hemithorax and a scimitar sign. Bronchoscopy, intra-arterial angiography of the aorta, pulmonary arteries and veins were performed.

A scimitar syndrome was diagnosed, with abnormal venous drainage and systemic arterial blood supply of the right lower lung zone.

Because of recurrent right-sided pneumonias and progressive shortness of breath, right-sided thoracotomy was performed. At operation, the right lung had no lobation. The right lower lung zone drained via a small normal pulmonary vein and via a large scimitar vein into the inferior vena cava, partially above and below the diaphragm. A normal superior pulmonary vein draining into the left atrium was present. The scimitar vein was reimplantated externally into the left atrium. The pulmonary artery to the right lower lung zone was hypoplastic. There were three systemic arteries arising from the abdominal aorta running to the right lower lung zone, which were ligated. 
Table 3. - Surgical management, postoperative course and follow-up

\begin{tabular}{llll}
\hline $\begin{array}{l}\text { Pat. } \\
\text { No. }\end{array}$ & Operation & Postoperative complication & Follow-up \\
\hline 1 & Right pneumonectomy, 1967 & None & Uneventful until 1987 \\
2 & $\begin{array}{l}\text { Reimplantation of vein, } \\
\text { ligation of arteries, 1972 }\end{array}$ & $\begin{array}{l}\text { Thrombosis of reimplanted vein, } \\
\text { needing pneumonectomy }\end{array}$ & Uneventful until 1975 \\
3 & $\begin{array}{l}\text { Resection of sequestered right, middle } \\
\text { and lower lobe, ligation of arteries, 1980 }\end{array}$ & None & Uneventful until 1986 \\
4 & $\begin{array}{l}\text { Reimplantation of vein, resection of } \\
\text { sequestered right lower lobe, ligation } \\
\text { of arteries, 1981 }\end{array}$ & $\begin{array}{l}\text { Fibrosis of reimplanted vein, } \\
\text { needing pneumonectomy }\end{array}$ & $\begin{array}{l}\text { Uneventful until 1994, } \\
\text { other than chronic bronchitis } \\
\text { and asthma }\end{array}$ \\
5 & None, 1988 & & Uneventful until 1994 \\
6 & None, 1989 & & $\begin{array}{l}\text { Uneventful until 1994 } \\
7\end{array}$ \\
\hline
\end{tabular}

Pat.: patient.

One month after the operation, lung scintigraphy showed almost absent perfusion of the entire right lung. A right pleural empyema was treated with daily needle aspirations.

At thoracotomy after 3 months, the reimplantated abnormal lung vein showed thrombosis. Right pneumonectomy was performed. There was no evidence of infarction in the resected lung. No further complications occurred. The follow-up until 1975 was uneventful.

\section{Patient No. 3}

In 1980, a 23 year old woman presented with recurrent chest infections and mild dyspnoea. A chest radiograph showed displacement of the heart and mediastinum to the right side, and a scimitar sign. Bronchoscopy, bronchography, intra-arterial angiography of the aorta, pulmonary arteries and veins were performed.

A scimitar syndrome was diagnosed, with abnormal venous drainage of the entire right lung and systemic arterial blood supply of the right lower and middle lobe.

Because of recurrent right-sided pneumonias and progressive shortness of breath, surgery was performed. At right-sided thoracotomy, the lower and middle lobe were hypoplastic, with a separate pleural layer. The venous drainage of the entire right lung was into the inferior vena cava, by two small scimitar veins, above the diaphragm. The right pulmonary artery was hypoplastic and situated on the dorsal side of the right main bronchus. Five abnormal systemic arteries, piercing through the diaphragm, supplied the sequestered right lower and middle lobe, which were ligated. The sequestered lung parenchyma was resected. Reimplantation of the small scimitar veins was not performed, because during the operation only a minor shunt could be calculated. The postoperative course was uneventful. During the follow-up period until 1986, there were no pulmonary problems.

\section{Patient No. 4}

In 1981, a 27 year old woman with chronic bronchitis and asthma was referred to our hospital with shortness of breath, recurrent chest infections and haemoptysis. The chest radiograph showed displacement of the heart to the right, with a scimitar sign. Bronchoscopy, bronchography, intra-arterial angiography of the aorta, pulmonary arteries and veins (fig. 1) were performed.

A scimitar syndrome was diagnosed, with abnormal venous drainage of the entire right lung and systemic arterial blood supply of the right lower lobe.

Because of recurrent right-sided pneumonias, rightsided thoracotomy was performed. At operation, the right lung anatomically resembled the left lung and the right lower lobe had a separate pleura. Drainage of the

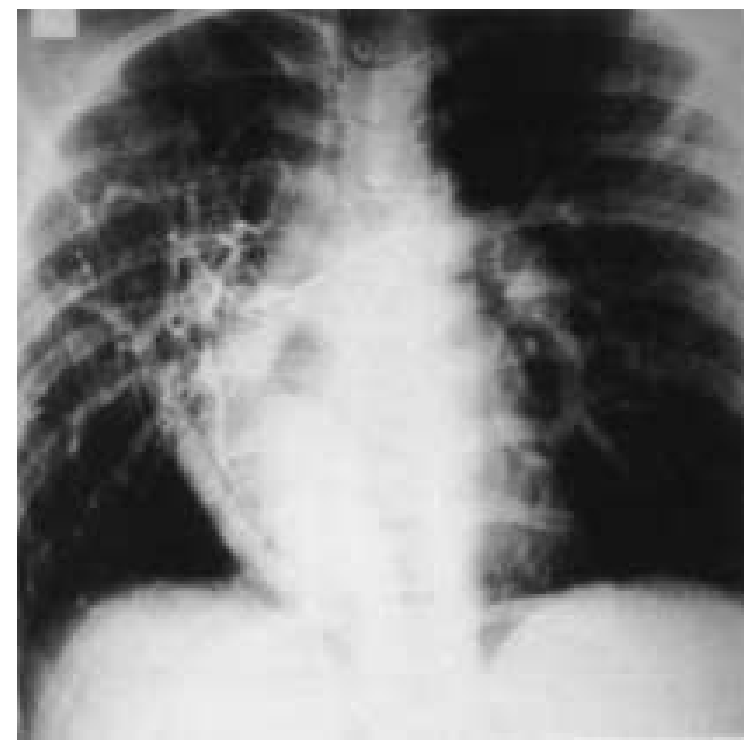

Fig. 1. - Intra-arterial pulmonary angiography of patient No. 4. The entire right lung appears to drain via a classic scimitar vein. 
right upper lobe occurred through the scimitar vein. No normal superior pulmonary vein was present. The right lower lobe drained partly through the scimitar vein and partly through a hypoplastic normal inferior pulmonary vein. The scimitar vein drained into the inferior vena cava above the diaphragm. It was redirected through the right atrium, using a dacron prosthesis, into the left atrium via the interatrial septum, during a short period of hypothermia and circulatory arrest. The right upper lobe was supplied by a hypoplastic pulmonary artery. Three systemic arteries from the abdominal aorta and a small branch of the pulmonary artery supplying the right lower lobe were ligated. Resection of the sequestered right lower lobe was performed.

Eleven months after operation, lung scintigraphy showed absent perfusion of the remaining right lung. At thoracotomy, the diverted scimitar vein showed extensive fibrosis, and an additional subdiaphragmatic aortic branch to the remaining part of the right lung, the former right upper lobe was found. A right completion-pneumonectomy was performed. No further complications occurred, although during follow-up until 1994, the patient is still very disabled due to severe chronic bronchitis and asthma.

\section{Patient No. 5}

In 1988, a 24 year old woman presented with a short history of mild shortness of breath during exercise, mainly due to hyperventilation. A chest radiograph showed a scimitar sign in an otherwise normal right hemithorax. Intravenous digital substraction angiography of the aorta, pulmonary arteries and veins (fig. 2) were performed.

A scimitar syndrome was diagnosed, with abnormal

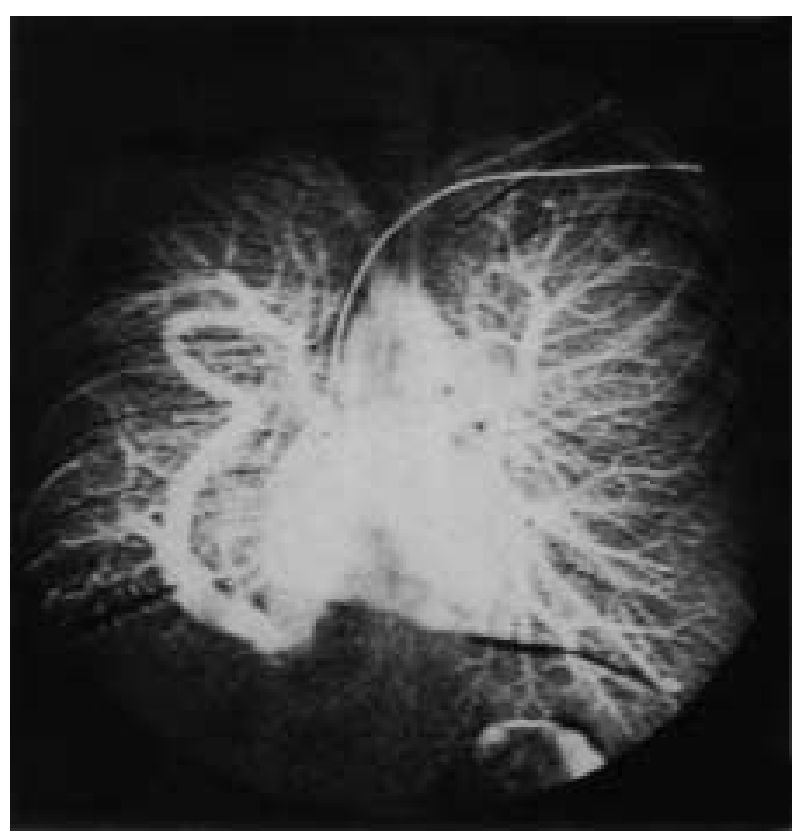

Fig. 2. - Intravenous digital substraction pulmonary angiography of patient No. 5. Showing a double arched vein draining into the left atrium and the inferior caval vein. drainage of the entire right lung, and hypoplasia of the right pulmonary artery, but without systemic arterial blood supply from the aorta. The patient refused cardiac catheterization. The patient's symptoms disappeared completely with breathing exercises. Follow-up until 1993 was uneventful.

\section{Patient No. 6}

In 1989, a 46 year old woman presented with mild shortness of breath during exercise. A chest radiograph showed displacement of the heart to the right, reduced volume of the right hemithorax and a scimitar sign. Intravenous digital substraction angiography of the aorta, pulmonary arteries and veins (fig. 3) were performed.

A scimitar syndrome was diagnosed, with abnormal venous drainage of the right lower lung zone, and hypoplasia of the right pulmonary artery, but without systemic arterial blood supply from the aorta. The patient refused cardiac catheterization. Because of the mild nature of the complaints and the absence of haemodynamic abnormalities at echocardiography, no operation was performed. The clinical picture was unchanged until 1993.

\section{Patient No. 7}

In 1992, a 5 year old boy was admitted to our hospital with mild recurrent chest infections. A chest radiograph and computed tomographic (CT) scan of the thorax showed two curved shadows, one right paracardial and one right paratracheal. Intra-arterial angiography of the

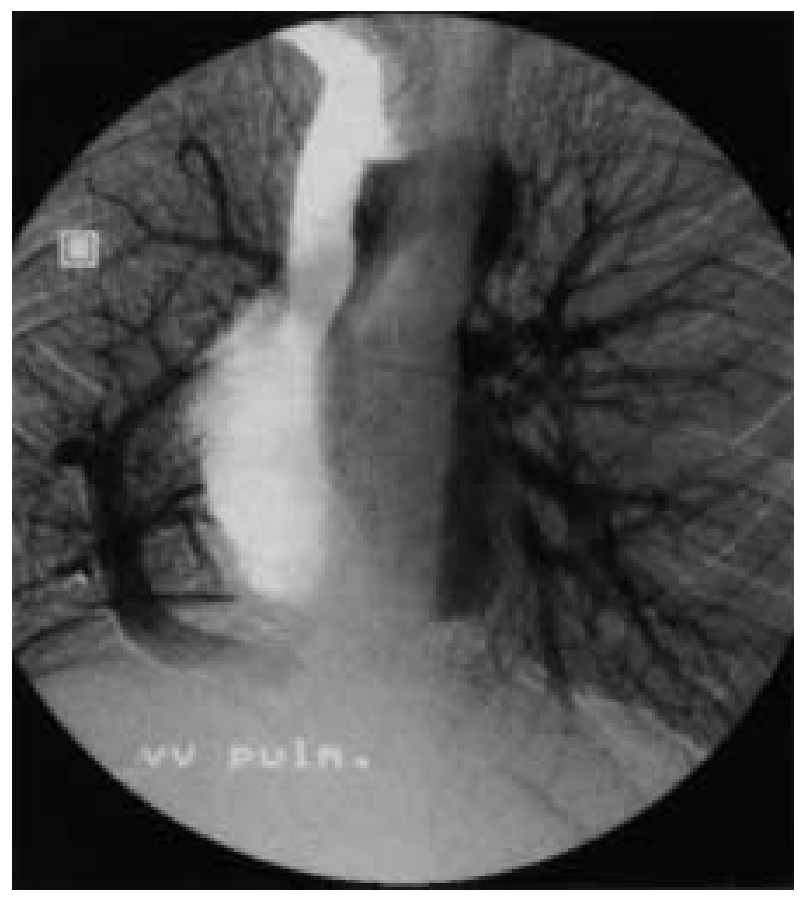

Fig. 3. - Intravenous digital substraction pulmonary angiography of patient No. 6. Showing a classic scimitar vein draining into the inferior caval vein and a normal right superior pulmonary vein. 


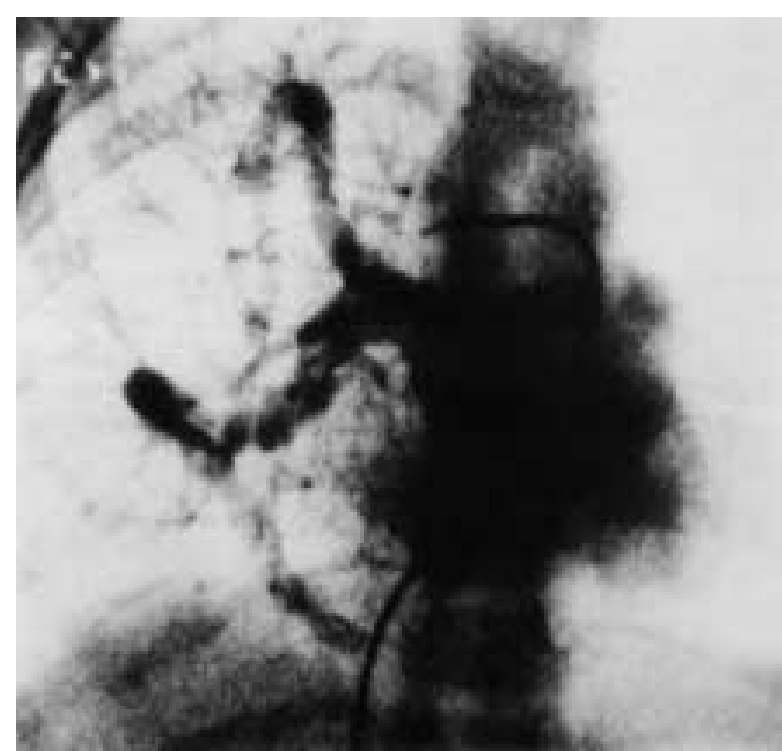

Fig. 4. - Intra-arterial pulmonary angiography of patient No. 7. Two abnormal veins of the right lung join and drain into the left atrium. The lower vein also drains into the inferior caval vein.

aorta, pulmonary arteries and veins (fig. 4) were performed.

A scimitar syndrome was diagnosed, with abnormal venous drainage of the entire right lung, hypoplasia of the right pulmonary artery and with one systemic artery from the abdominal aorta running to the right lower lung zone.

Thoracotomy was not performed, because of the mild nature of the infections and the small left/right shunt of $20 \%$. Two years after admission, no periods of severe chest infection have reoccurred.

\section{Discussion}

We describe seven patients (6 females, 1 male) with a right-sided scimitar syndrome. A female predominance has already been found in other studies [3, 6, 19].

Two kinds of scimitar vein were recognized. A simple classic scimitar vein running from the middle of the right lung to the cardiophrenic angle (patients Nos 1-4 and 6) (figs. 1 and 3); patient No. 3 had two such veins. The drainage of the right upper lung zone of these patients also occurred via the scimitar vein in patient Nos 3 and 4, via a normal superior pulmonary vein into the left atrium in patient Nos 2 and 6, and via an abnormal vein into the superior caval vein and a normal superior pulmonary vein in patient No. 1 (table 1 ).

The other type of scimitar vein (patients Nos 5 and 7 ) is a double arched vein in the upper and lower lung zone, with ample drainage into the left atrium and inferior caval vein (figs. 2 and 4) (table 1). Angiographically, no normal right pulmonary veins, draining the right upper lung zone, were demonstrated in these two patients. More or less comparable veins have been described previously [5-7, 10, 20-22].
Five of our patients had proven systemic arterial blood supply to the right lower lung zone and sometimes the middle lung zone, all branching from the abdominal aorta. Patient No. 4 also had systemic blood supply of the right upper lung zone (table 1). In two patients, no systemic artery blood supply to the right lung was seen with intravenous digital substraction angiography of the aorta. However, aortography was not performed; therefore, small systemic arteries could remain undetected. In contrast to previous studies, none of our patients showed congenital cardiac or extrapulmonary malformations [4, 8, 19].

Angiographic studies of the aorta, pulmonary arteries and veins, bronchoscopy, bronchography, spirometry and lung scintigraphy or bronchospirometry (tables 1 and 2) are essential in the diagnostic procedure of patients with the scimitar syndrome, especially when surgery is considered. A complete picture of the vascular, bronchial and functional abnormalities must be obtained, otherwise the surgeon may be surprised by unexpected anatomical problems, illustrated by patient No. 4, in whom a systemic artery remained undetected until the second thoracotomy. Cardiac catheterization is the method of choice to measure pulmonary artery pressure and to calculate the left/right shunt. CT scan of the thorax may be useful to detect bronchiectasis. However, we prefer bronchography because it also provides information about the precise bronchial anatomy.

There are two indications for surgical intervention: 1) large left/right shunt exceeding $50 \%$, resulting in pulmonary hypertension and heart failure [4, 6, 19, 22, 23]; and 2) lung sequestration and/or recurrent right-sided chest infections [4, 6, 24, 25].

Surgical treatment is best managed in two steps: 1) the anomalous systemic arteries are ligated and the scimitar vein is reimplanted into the left atrium; and 2) resection of sequestered or chronically infected lung parenchyma is performed.

Four of our patients underwent thoracotomy, because of recurrent right-sided pneumonias, with sequestration of lung parenchyma in two patients (patients Nos 3 and 4) (table 3). In these four patients, the abnormal systemic arteries were ligated. Resection of the sequestered part of the lung was performed in two patients (patients Nos 3 and 4). In one patient, (patient No. 1) a right pneumonectomy was performed. In one patient (patient No. 2) no resection was performed because the infected part of the lung was not well demarcated due to absent lobation.

In two patients, an attempt was made to redirect the anomalous vein to the left atrium. In patient No. 4, the vein was deviated through the atrial septum into the left atrium, a technique which has been described in several other cases. In some of these cases, if the length of the scimitar was limited a patch sutured around an opening in the atrial septum or an interposition graft was used to make the connection with the left atrium [3, 5, 14 , $19,23,26,27]$. In patient No. 2 , the scimitar vein was reimplanted externally into the left atrium, a method which, to our knowledge, has not been described previously. 
However, several months after both operations, the redirected veins were obstructed by thrombosis and fibrosis despite the use of anticoagulation. Both patients underwent pneumonectomy. It is possible that this major postoperative complication is caused by inadequate pulmonary arterial blood supply.

Based on our limited experience and the results in the literature, angiography of aorta, pulmonary arteries and veins, bronchoscopy, bronchography, spirometry, lung scintigraphy or bronchospirometry and measurement of the left/right shunt are essential in the management of patients with scimitar syndrome if surgery is considered. Surgical intervention should be limited to those patients with lung sequestration or recurrent serious chest infections of the affected lung or those with right ventricle overload due to a major left/right shunt. Thrombosis or fibrosis of the redirected scimitar vein is a serious complication of the surgical reimplantation procedure, often needing rethoracotomy with resection of the remaining lung.

Acknowledgment: The authors thank the Dept of Paediatric Cardiology of the University Hospital Rotterdam for the use of the angiographic studies of patient No. 7 .

\section{References}

1. Cooper G. Case of malformation of the thoracic viscera consisting of imperfect development of the right lung and transposition of the heart. London Med Gaz 1836; 18: 600-601.

2. Neill CA, Ferenca C, Sabiston DC. The familial occurrence of hypoplastic right lung with systemic arterial supply and venous return, "scimitar syndrome". Bull Johns Hopkins Hosp 1960; 107: 1-21.

3. Honey M. Anomalous pulmonary venous drainage of right lung to inferior vena cava ("scimitar syndrome"): clinical spectrum in older patients and role of surgery. Q J Med (new series XLVI) 1977; 184: 463-483.

4. Canter CE, Martin TC, Spray TL, Weldon CS, Stauss AW. Scimitar syndrome in childhood. Am J Cardiol 1986; 58: 652-654.

5. Kuiper-Oosterwal CH, Moulaert A. The scimitar syndrome in infancy and childhood. Eur J Cardiol 1973; 1: 55-61.

6. Sanger PW, Taylor FH, Charlotte FR. The scimitar syndrome: diagnosis and treatment. Arch Surg 1963; 86: 84-91

7. Gazzaniga AB, Matloff JM, Harken DE. Anomalous right pulmonary venous drainage into the inferior vena cava and left atrium. J Thorac Cardiovasc Surg 1969; 57: 251-254.

8. Woody JN, Graham TP, Bradford WD, Sabiston DC, Canent RV, Durham NC. Hypoplastic right lung with systemic blood supply and anomalous pulmonary venous drainage: reversal of pulmonary hypertension with surgical management in infancy. Am Heart J 1972; 83: 8288 .

9. Huebsch P, Neuhold A, Mayr H, Gloger D. Anomalous pulmonary venous drainage shown by duplex sonography, computed tomography and plain radiography. Thorax 1989; 44: 63-65.

10. Hayward RH, Martt JM, Brewer LM, Immon TM, Best
EB. Surgical correction of the vena cava-bronchovascular complex: developmental pulmonary, arterial, and venous anomalies with accessory diaphragm. J Thorac Cardiovasc Surg 1972; 64: 203-210.

11. D'Cruz IA, Arcilla RA. Anomalous venous drainage of the left lung into the inferior vena cava: a case report. Am Heart J 1964; 67: 539-544

12. Mardini MK, Sakati NA, Nyhan WL. Anomalous left pulmonary venous drainage to the inferior vena cava and through the pericardiophrenic vein to the inominate vein: left-sided Scimitar syndrome. Am Heart J 1981; 101: 860-862.

13. Kissner DG, Sorkin RP. Anomalous pulmonary venous connection, medical therapy. Chest 1986; 89: 752-754.

14. Mathey J, Galey JJ, Logeais Y, et al. Anomalous pulmonary venous return into inferior vena cava and associated bronchovascular anomalies (the scimitar syndrome): report of three cases and review of the literature. Thorax 1968; 23: 398-407.

15. Snellen HA, van Ingen HC, Hoefsmit ChM. Patterns of anomalous pulmonary venous drainage. Circulation 1968; 38: 45-63.

16. Clements BS, Warner JO. Pulmonary sequestration and related congenital bronchopulmonary vascular malformations: nomenclature and classification based on anatomical and embryological considerations. Thorax 1987; 42: 401-408.

17. Clements BS, Warner JO, Shinebourne EA. Congenital bronchopulmonary vascular malformations, clinical application of a simple anatomical approach in 25 cases. Thorax 1987; 42: 409-416.

18. Fraser RG, Paré PJA, Paré PD, Fraser RS, Genereux GP. Anomalies of both arteries and veins: hypogenetic lung (scimitar) syndrome. In: Diagnosis of Diseases of the Chest, 3rd edn. Philadelphia, Saunders LD. 1989; pp. 748-752.

19. Folger GM. The scimitar syndrome: anatomic, physiologic, developmental and therapeutic considerations. Angiology 1976; 27: 373-407.

20. Haworth SG, Sauer K, Buhlmeyer K. Pulmonary hypertension in scimitar syndrome in infancy. Br Heart $J$ 1983; 50: 182-189.

21. Osborn GA, Silverman JF. Unusual venous drainage pattern in the scimitar syndrome. Radiology 1974; 113: 601-603.

22. Mohiuddin SM, Levin HS, Runco V, Booth RW. Anomalous pulmonary venous drainage: a common trunk emptying into the left atrium and inferior vena cava. Circulation 1966; 24: 46-51.

23. Yonehiro EG, Hallman GL, Cooley DA. Anomalous pulmonary venous return from a hypoplastic right lung to the inferior vena cava (scimitar syndrome): report of successful correction and review of surgical treatment. Cardiovasc Res Center Bull 1966; 4: 106-117.

24. Farnsworth SG, Sauer K, Buhlmeyer K. The spectrum of scimitar syndrome. J Thorac Cardiovasc Surg 1974; 68: $37-42$.

25. Alivizatos P, Cheath T, de Leval M, Stark J. Pulmonary sequestration complicated by anomalies of pulmonary venous return. J Ped Surg 1985; 20: 76-79.

26. Kirklin JW, Ellis FH, Wood EH. Treatment of anomalous pulmonary venous connections in association with interatrial communications. Surgery 1956; 39: 389392.

27. Tsuchida K, Anzai N, Hashimoto A, Fukushima Y, Yamada M. Intra-atrial conduit repair in scimitar syndrome. Chest 1987; 92: 1120-1122. 